\title{
A COMPARISON BETWEEN TWO DIFFERENT TYPES OF ATTACHMENTS IN IMPLANT RETAINED MANDIBULAR OVERDENTURES (A STRESS ANALYSIS STUDY)
}

\author{
Heba E. Khorshid*
}

\begin{abstract}
Background: The target of this in vitro study was to evaluate the distribution of stresses using strain gauges around two mandibular implants installed in the inter-foraminal region retaining an overdenture with two different types of attachments; ball attachment and magnet attachment.

Materials and Methods: In this Invitro study, a mandibular conventional denture model was constructed using heat cured acrylic resin. In the canine region, two box shaped preparations with a $1 \mathrm{~mm}$ thickness buccally, lingually, mesialy and distaly were done into which two dummy implants were mounted and bonded to the model using self-cure acrylic resin. Over each surface, strain gauges of length $5 \mathrm{~mm}$, resistance of $120.4 \pm 0.4 \Omega$ and a gauge factor of $2.09 \pm 1 \%$, were anchored. Unilateral and bilateral vertical static load of $100 \mathrm{~N}$ using a universal testing machine was applied onto both types of overdentures; one retained by the ball and one by the magnet and 10 readings were recorded for each attachment.
\end{abstract}

Results: When comparing the micro strain mean values of both groups while applying strain both bilaterally and unilaterally, the study has shown that there was a statistically significant difference in the mean values of micro strain between the Ball and Magnet attachment in the nonloading side where $(\mathrm{p}<0.001)$. The highest mean value of micro strain was found in Ball attachment while the least mean value of micro strain was found in the Magnet in both events. Results also revealed that there was a statistically significant difference in mean values of micro strain between the Loaded side and the Unloaded side where $(\mathrm{p}<0.001)$ where The highest mean value of micro strain was found in the Loaded side while the least mean value of micro strain was found in Unloaded side in both groups.

Conclusion: Within the limitations of this study, it can be concluded that ball attachments induce higher micro-strain on the bone implant interface than the magnet attachment.

\footnotetext{
* Lecturer, Department of Prosthodontics and Implantology, Faculty of Oral and Dental Medicine, Cairo University.
} 


\section{INTRODUCTION}

The ideal goal for modern dentistry is to restore the patient's normal facial contour, function, comfort, esthetics, speech and health. ${ }^{[1]}$ The increasing need and use of dental implant-related treatments result from the combined effect of a number of factors as mentioned by Misch $^{(1)}$. The use of dental implants to restore completely edentulous patients has greatly improved patient satisfaction, masticatory performance, health of remaining supporting structures and overall quality of life for edentulous patients ${ }^{(2-4)}$. Implant retained overdentures using two inter-foraminal implants have been recognized to be the standard of care for completely edentulous patients since $2002^{(2)}$ for being simple, less invasive, cost-effective and successful ${ }^{(5,6)}$.

Attachments used to retain Implant supported overdentures can be mainly classified into splinted attachments or un-splinted attachments ${ }^{(7)}$. The unsplinted attachments have a greater advantage of less inter-arch space requirement, ease of cleaning, cheaper and easier to construct than the splinted attachments ${ }^{(8,9)}$.

Ball and socket attachment is the most well-known un-splinted attachment to retain a mandibular overdenture, because of its simplicity and low cost ${ }^{(10)}$. Masticatory functional load are normally transferred through the implants to the peri-implant bone ${ }^{(11)}$. Brunski ${ }^{[12]}$ declared that controlling the functional forces is a contributing factor for obtaining success of implant. In a series of experiments, Miyata et al. ${ }^{[13]}$ conducted experiments that showed that occlusal overload can result in marginal bone loss around oral implants with no inflammation in the peri-implant tissues.

There are several types of attachments including bars, rigid and resilient telescopes, magnets and stud attachments ${ }^{(14,15)}$. Magnetic attachments have the advantage of self-aligning properties as well as their low vertical profile rendering them particularly useful in patients with physical disabilities ${ }^{(16)}$ or where inter-occlusal space is a problem ${ }^{(17)}$. However, Magnet attachments have low resistance to lateral forces due to their ability to immediately disengage thus eliminates the lateral forces and conveys the least stresses conducted to the per-implant bone when compared with other attachments ${ }^{(18)}$. This means that their retentive forces of were less than other attachments ${ }^{(18,19)}$. According to Tokuhisa et al. and Takeshita et al. ${ }^{(18,19)}$, Magnet attachments were found to exhibit the least strains under occlusal loading when compared to ball and bar attachments. Moreover, Ball attachments for implant-retained overdentures were associated with significant mandibular denture base deformation over the implants compared to Locator attachments ${ }^{(20)}$. In a recent study perfomed by Takahashi et al. ${ }^{(21)}$, results demonstrated that Ball attachments caused the greatest amount of strain, while magnet attachments caused the least amount under all conditions. Another great advantage of magnet attachment is that their retentive property is never ending due to the very long time span of its magnetic field in comparison with other stud attachments which are subjected to component wear due to friction ${ }^{(18)}$.

Despite all these studies, a systemetic review performed by Anas el Wegoud et al. (22) concluded that there is still insufficient evidence to support bar or ball attachment to be used with implant-supported overdentures in completely edentulous patients to improve patient satisfaction and prosthesis retention.

Analysis of the stresses transmitted to the peri-implants can be done using several methods including photo elastic, strain gauge and finite element analysis. Strain gauges work by calculating the distortion of a body by computing its electrical resistance alteration providing quantitative data (23). It will then transform the change in electrical resistance to an electrical voltage which can be measured with great accuracy at the place where the strain gauge is placed ${ }^{(24,25)}$. However, the size and placement of the strain gauges are critical and could be a limiting factor ${ }^{(23)}$. 


\section{MATERIALS AND METHODS}

\section{Model construction and Implant placement}

In this In vitro study, a mandibular conventional denture model was constructed using heat cured acrylic resin". In the canine region, two box shaped preparations with a $1 \mathrm{~mm}$ thickness buccally, lingually, mesialy and distaly were done into which two dummy implants were mounted and bonded to the model using self-cure acrylic resin**. Over each surface, strain gauges of length $5 \mathrm{~mm}$, resistance of $120.4 \pm 0.4 \Omega$ and a gauge factor of $2.09 \pm 1 \%$, were anchored. Unilateral and bilateral vertical static load of $100 \mathrm{~N}$ using a universal testing machine was applied onto both types of overdentures; one retained by the ball and one by the magnet and 10 readings were recorded for each attachment.

In this In vitro study, a completely edentulous mandibular model was constructed using heat cured acrylic resin using a silicon mold duplicated from a conventional mandibular cast. A properly adapted and stable trial denture base was then fabricated using self cured acrylic resin on this acrylic resin mold. Teeth selection and set up was then performed on the trial denture base following the conventional guide lines of complete denture construction. Waxing up, flasking packing and curing was then performed in a conventional manner followed by de-flasking and finishing and polishing of the final acrylic mandibular denture. The mandibular denture was then duplicated into a clear acrylic resin stent after being checked for proper fit and seating on the acrylic model. Drilling of the clear acrylic resin was carried out from the right canine area and left canine area while keeping the labial and lingual surface intact. Two mock implants were then mounted on the right and left canine area using a surveyor milling machine $^{* * *}$ to ensure parallelism of the two implants. The mock implants ${ }^{* * * *}$ were connected to the cast by placing a soft mix of self-cure acrylic resin in the drilled holes during installation of the implants.

\section{Model Preparation for Strain Gauges Placement}

The acrylic resin was prepared using a fissure bur to create a box of $1 \mathrm{~mm}$ thickness around each of the two implants with four surfaces: Buccal (B), Lingual (L), Mesial (M), and Distal (D). The walls prepared were smooth (smoothened with sandpaper to avoid incremental strains) flat and parallel to the long axis of each installed implant. Since the used strain gauges were temperature-compensated for plastics, a dummy gauge was not used for temperature compensation ${ }^{(26)}$ (Stegaroiu et al., 2004).

The Strain gauges ${ }^{* * * * *}$ installed were $5 \mathrm{~mm}$ in length, resistance of $120.4 \pm 0.4 \Omega$ and a gauge factor of $2.09 \pm 1 \%$. The strain gauges were labeled according to each surface it was attached to then adhered to the four prepared surfaces using a Cyanoacrylate based adhesive ${ }^{* * * * * *}$ and was left 24 hours to fully set. The Stain gauges were secured in special Channels prepared on the sides of each model to prevent no any damages or dislodgment during the measurement procedure.

\section{Attachments pick up}

The two attachments used in this in vitro study were the; Ball and Magnet attachment. First, the two ball attachments with their metal housing and nylon cap were placed over the two implants. The ball attachments were screwed with a torque of $25 \mathrm{Ncm}$ (Fig.1A). Two holes corresponding to each of the ball attachment with their metal housing were

\footnotetext{
* Clear heat cured acrylic resin, Acrostone, Egypt

** Cold cure Acrylic resin , Acrostone, Egypt

*** Bego Bremer Goldschagerei Wihl. Herbst, Bremen, Germany

**** Osteoseal dental implants, California, USA

***** Kyowa strain gauges, KFG-3-120-c1-11L1M2R, Japan

****** CC-33 strain gauge cement, Kyowa electronic instruments co., Japan.
} 
prepared on the fitting surface of the lower denture. The complete denture was checked for complete seating and lack of any interference between the metal housing and fitting surface. A rubber dam was positioned around each of the ball attachments to block the undercuts during pick up. Pick up procedures were initiated for the ball attachment followed by loading and measurements. A thin mix of self-cure acrylic resin was placed through the drilled holes of the properly seated denture. The denture was removed from the cast with the metal housing and nylon cap and was checked to be properly picked up in the fitting surface of the denture (Fig. 1 B).

Measurements of the strain around each implant were then recorded for the ball attachment group. After all of the measurements were recorded, the metal housing with nylon cap along with the surrounding acrylic resin was then removed from the fitting surface of the denture.

The ball attachment was unscrewed from the acrylic resin model, and the two Magnet attachments of $2 \mathrm{~mm}$ gingival height were screwed to the two implants (Fig. $1 \mathrm{C}$ ) with a torque of $35 \mathrm{Ncm}$. The magnetic keeper was placed over the attachment. Pick up of the Magnet attachments was done in a similar way to that done for the ball attachments (Fig. 1 D). The denture with the Magnet attachment was then used to measure all of the strains around each implant for this group.

\section{Loading and Strain measurements}

In this in vitro study, Unilateral and bilateral vertical static load of $100 \mathrm{~N}$ for 15 seconds at a cross head speed of $0.5 \mathrm{~mm} /$ minute to simulate implant retained occlusal loads was performed using a universal testing machine.* A small round bur was used to prepare a small notch in the central fossa of the first molar tooth on the right and left sides which functioned as a repeatable and standardized point of load application. (Fig. 2). An I-shaped load applicator was utilized for obtaining the unilateral loading readings where the load applicator was applied on the prepared notch of the first molar on the left side. The left side was considered to be the loading/working side, while the right side was considered to be the non-loading/non-working side. A $\mathrm{T}$ shaped load applicator was utilized for obtaining the bilateral loading readings where the load applicator was simultaneously applied on the prepared notch of the first molar on both the right and left sides of the arch (Fig. 3).

A multichannel strain meter** (Fig. 4) was connected to the terminal ends of the strain gauge wires. Using special software***, this Multichannel strain meter was used to measure the microstrains transmitted through each of the four strain gauges. Ten readings were taken for each of the two attachments allowing at least a five minute interval between each reading for heat dissipation. The results obtained were recorded, tabulated and statistically analyzed.

\section{Statistical Method}

The mean and standard deviation values were calculated for each group. Data were explored for normality using Kolmogorov-Smirnov and Shapiro-Wilk tests and showed parametric (normal) distribution. Independent sample-t test was used to compare between independent samples. The significance level was set at $\mathrm{P} \leq 0.05$. Statistical analysis was performed with IBM ${ }^{\circledR}$ SPSS ${ }^{\circledR}$ Statistics Version 20 for Windows.

\footnotetext{
* Lloyd LR5K instrument, Fareham, Hampshire, UK ** Model 8692, Tinsely precision instruments, Surrey, UK *** Kyowa Electronic Instruments Co.,Ltd, Japan
} 


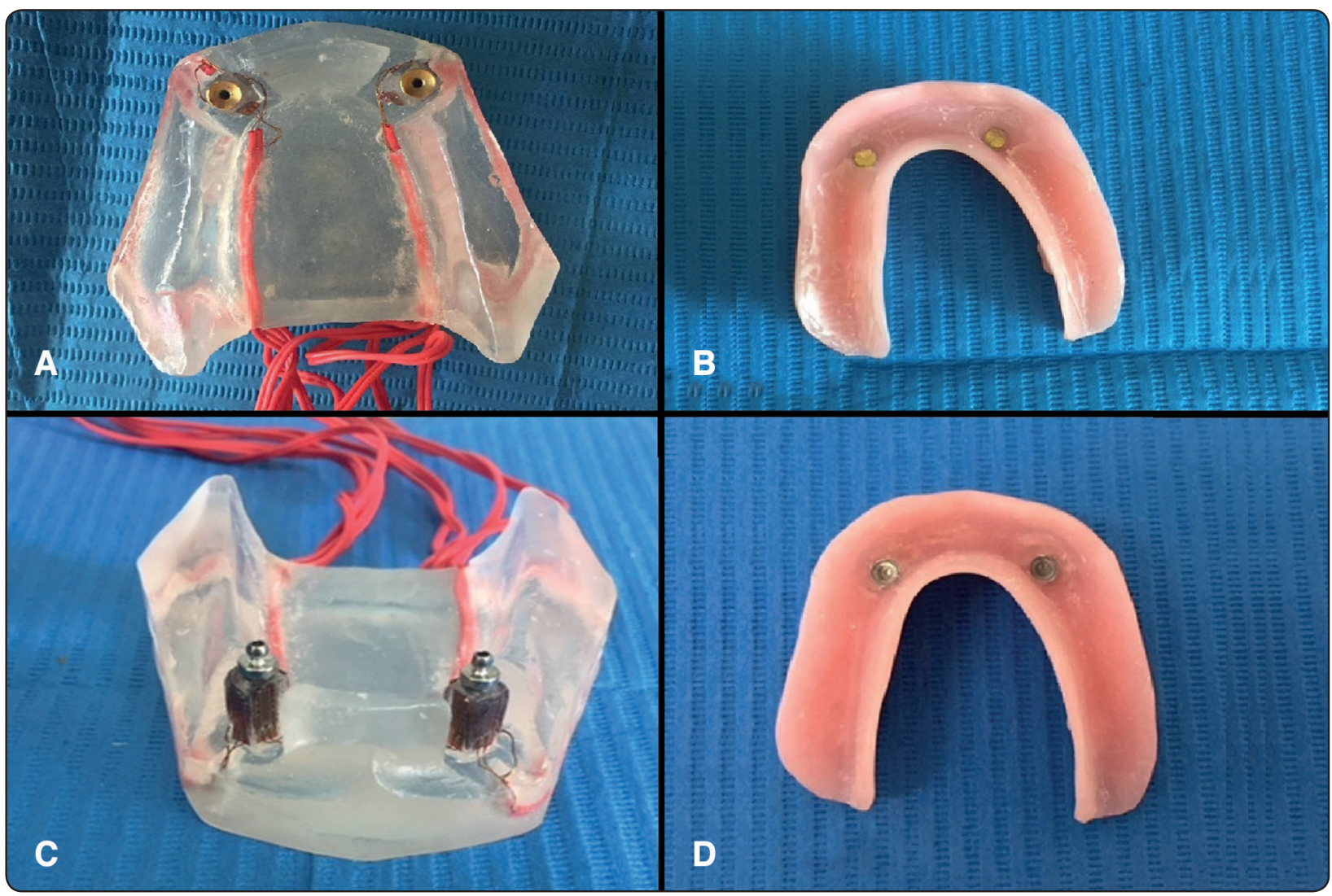

Fig (1) A) Magnet attachment screwed to the cast. B) Magnet keeper picked up in fitting surface of the denture C) Ball attachment screwed to the cast. D) Nylon cap picked up in the denture.
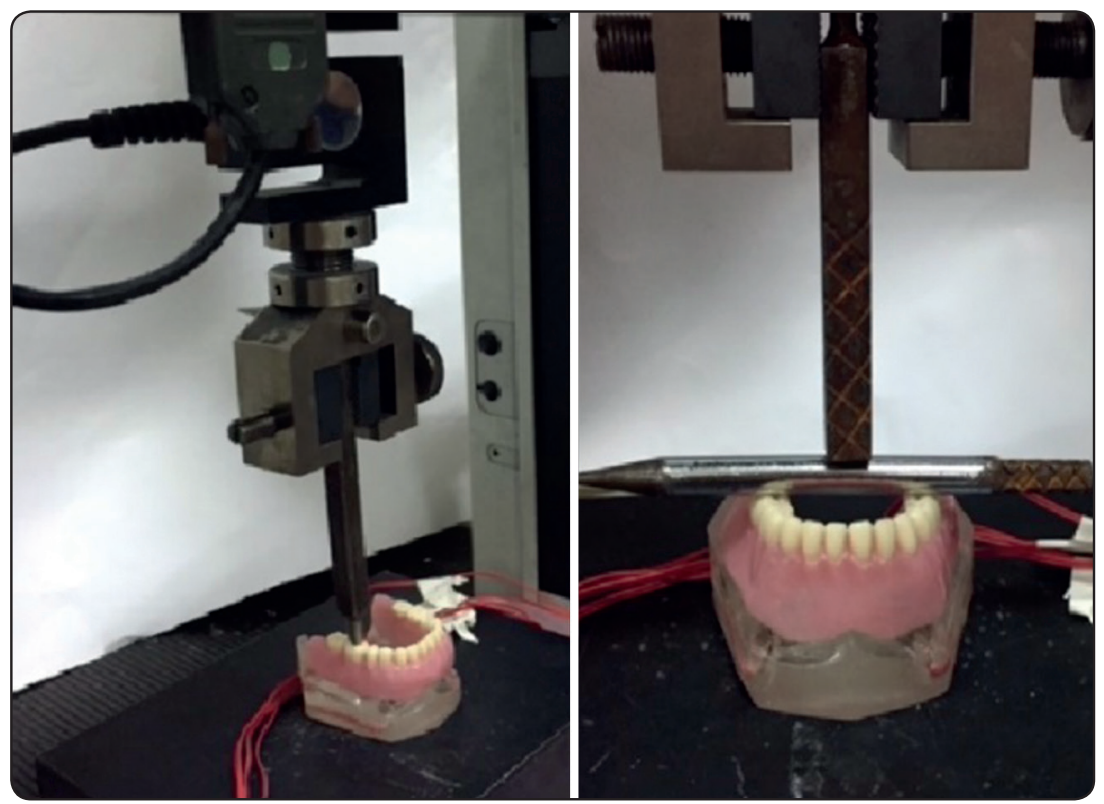

Fig (3) The Universal testing machine applying unilateral load

Fig (4) The Universal testing machine applying bilateral load 


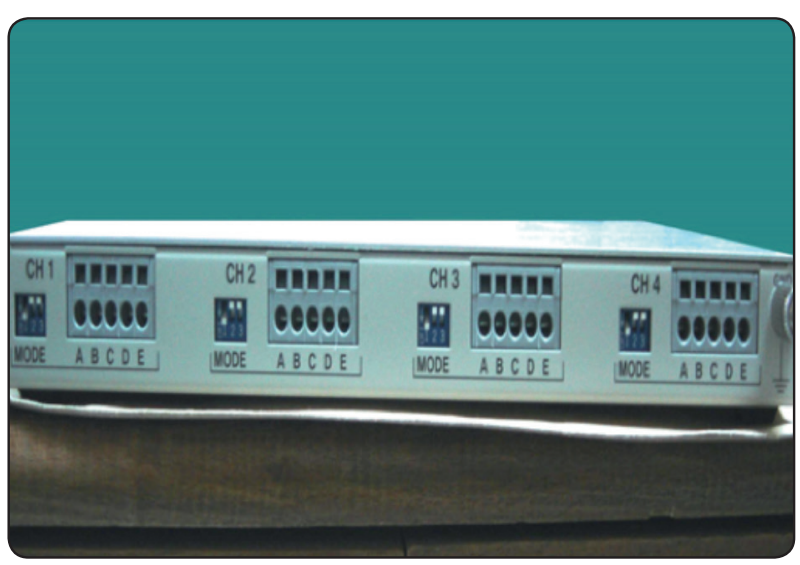

Fig (5) Multichannel Strain meter

\section{RESULTS}

There was no statistically significant difference in the mean micro-strain measurements recorded at the different surfaces; Buccal. Mesial, Distal, and Lingual for each implant. For that reason all of the four surfaces were added up to represent a mean micro-strain recorded for each implant.

\section{Unilateral loading:}

Regarding the Ball attachment group, there was a statistically significant difference in mean values of micro strain between the Loaded side and the Unloaded side where $(\mathrm{p}<0.001)$. The highest mean value of micro strain was found in Loaded side while the least mean value of micro strain was found in
Unloaded side. (Table 1)

As for the for the Magnet attachment, there was a statistically significant difference in mean value of micro strain between Loaded side and Unloaded side where $(p<0.001)$. The highest mean value of micro strain was found in the Loaded side while the least mean value of micro strain was found in Unloaded side. (Table 1) (Fig. 5)

When comparing the micro strain mean values of both groups while applying strain unilaterally, the study has shown that there was a statistically significant difference in the mean values of micro strain between the Ball and Magnet attachment in the non-loading side where $(\mathrm{p}<0.001)$. The highest mean value of micro strain was found in Ball attachment while the least mean value of micro strain was found in the Magnet attachment.

Additionally, statistical analysis of the micro strain mean values of both groups while applying strain unilaterally, showed a statistically significant difference in the mean of micro strain between the Ball and the Magnetic attachment at the loaded side where $(\mathrm{p}<0.001)$. The highest mean value of micro strain was found in the Ball while the least mean value of micro strain was found in Magnet attachment. (Table 1) (Fig. 8)

TABLE (1): The mean, standard deviation (SD) values of micro strain of unilateral loading of both groups.

\begin{tabular}{|c|c|c|c|c|c|}
\hline \multirow{2}{*}{ Variables } & \multicolumn{5}{|c|}{ Unilateral loading } \\
\cline { 2 - 5 } & \multicolumn{2}{|c|}{ Unloaded side } & \multicolumn{2}{c|}{ Loaded side } & \multirow{2}{*}{ P-value } \\
\cline { 2 - 6 } & Mean & SD & $864.50^{\mathrm{aA}}$ & 38.14 & $<0.001^{*}$ \\
\hline Ball attachment & $229.50^{\mathrm{aB}}$ & 33.52 & $330.25^{\mathrm{bA}}$ & 56.60 & $<0.001^{*}$ \\
\hline Magnetic attachment & $153.50^{\mathrm{bB}}$ & 40.53 & & $<0.001^{*}$ & \\
\hline
\end{tabular}

Means with different small letters in the same column indicate statistically significance difference; means with different capital letters in the same row indicate statistically significance difference. *; significant $(p<0.05) \quad$ ns; non-significant $(p>0.05)$ 


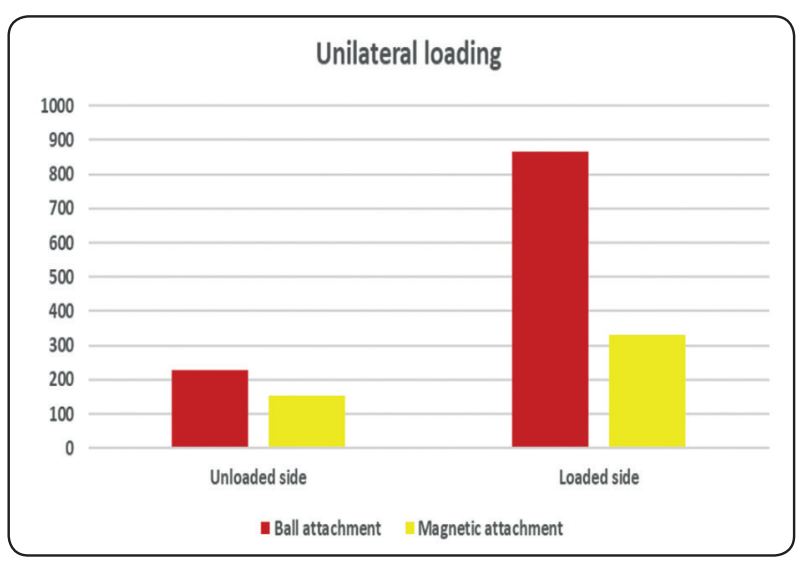

Fig. (6): Bar chart representing means of micro strain of unilateral loading in both groups

\section{Bilateral loading:}

Regarding the Ball attachment group, there was a statistically significant difference in mean values of micro strain between the Loaded side and the Unloaded side where $(\mathrm{p}<0.001)$. The highest mean value of micro strain was found in Loaded side while the least mean value of micro strain was found in Unloaded side. (Table 2)

As for the for the Magnet attachment, there was a statistically significant difference in mean value of micro strain between Loaded side and Unloaded side where $(p<0.001)$. The highest mean value of micro strain was found in the Loaded side while the least mean value of micro strain was found in Unloaded side.

When comparing the micro strain mean values of both groups while applying strain bilaterally, the study has shown that there was a statistically significant difference in the mean values of micro strain between the Ball and Magnet attachment in the non-loading side where $(\mathrm{p}<0.001)$. The highest mean value of micro strain was found in Ball attachment while the least mean value of micro strain was found in the Magnet attachment.

Additionally, statistical analysis of the micro strain mean values of both groups while applying strain bilaterally, showed a statistically significant difference in mean of micro strain between the Ball and the Magnetic attachment at the loaded side where $(\mathrm{p}<0.001)$. The highest mean value of micro strain was found in the Ball while the least mean value of micro strain was found in Magnet attachment. (Table 2)

TABLE (2): The mean, standard deviation (SD) values of micro strain of Bilateral loading of both groups.

\begin{tabular}{|c|c|c|c|c|c|}
\hline \multirow{2}{*}{ Variables } & \multicolumn{5}{|c|}{ Bilateral loading } \\
\cline { 2 - 5 } & \multicolumn{2}{|c|}{ Unloaded side } & \multicolumn{2}{c|}{ Loaded side } & \multirow{2}{*}{ P-value } \\
\cline { 2 - 6 } & Mean & SD & Mean & SD \\
\hline \multirow{2}{*}{ Ball attachment } & $368.75^{\mathrm{aB}}$ & 23.45 & $635.00^{\mathrm{aA}}$ & 80.48 & $<0.001^{*}$ \\
\hline \multirow{2}{*}{ Magnetic attachment } & $68.25^{\mathrm{bB}}$ & 8.63 & $127.00^{\mathrm{bA}}$ & 14.73 & $<0.001^{*}$ \\
\hline P-value & & $<0.001^{*}$ & & $<0.001^{*}$ & \\
\hline
\end{tabular}

Means with different small letters in the same column indicate statistically significance difference; means with different capital letters in the same row indicate statistically significance difference. *; significant $(p<0.05) \quad n s ;$ non-significant $(p>0.05)$ 


\section{DISCUSSION}

In the current study, all circumstances were standardized; the same denture was used for pickup of both attachments to decrease any variables such as the presences of any porosities or deformations in the denture base that might induce micro-strain.

In this current study, unilateral load was done to mimic the preferred chewing side of each patient while bilateral loading was done to mimic bilateral chewing. A wide range of multi-directional occlusal forces will be applied to implant supported overdentures as a result of masticatory and functional loads which will in turn induce strain to the peri-implant bone. ${ }^{(27-29)}$ The closer the implant to the load applied, the more is the strain transmitted to it explaining the reason why there was a statistically significant higher micro-strain records on the loaded side for both attachments utilized in this study. ${ }^{(30)}$ Studies have also shown a relationship between the amount of strain transmitted to the bone/implant complex and the type of attachment utilized ${ }^{(18,20)}$. The different designs and materials used in each type of attachment have an effect on the amount of stresses received by the peri-implant bone during masticatory loads ${ }^{(31)}$. Loading was also performed on the first molar as this is considered the center of occlusion where the maximum forces by the elevator muscles occur. ${ }^{(32)}$ Results of this study showed higher strain in the loaded side than the unloaded side in both attachment groups which is agreeable with previous studies performed ${ }^{(18,32)}$.

Results of this study also demonstrated a statistically significant higher mean micro-strain in the ball attachment in the loaded side than the mean micro-strain of the magnet attachment when subjected to unilateral loading. The ball and socket attachment act as a fulcrum during loading of the overdenture ${ }^{(33)}$ with the lack of any intervening space between its components thus inducing higher strain on the bone/implant complex. This was in accordance with a finite element analysis study which reported high stresses transmitted on the loading side of ball attachments ${ }^{(31)}$. The same findings were also recorded on the unloaded side where there was a statistically significant higher mean micro-strain in the ball attachment than the mean micro-strain of the magnet attachment when subjected to unilateral loading which was also explained by a the same study performed .

This study also demonstrated higher statistical significant mean micro-strain values in the loaded side (left side) than the unloaded side in both types of attachments. According to Chao et al. and Mericske-Stern et $\mathrm{al}^{(34,35)}$, the overdenture will tend to rotate anteriorly around a fulcrum line when posterior loads are applied. As a result of this rotation, the denture dis-engaged from the right side thus reduction in the micro-strain transmitted to the right implant.

When comparing the micro strain mean values of both groups while applying strain bilaterally, the study has shown that there was a statistically significant difference in the mean values of micro strain between the Ball and Magnet attachment in the non-loading side where the highest mean value of micro strain was found in Ball attachment while the least mean value of micro strain was found in the Magnet attachment.

Additionally, statistical analysis of the micro strain mean values of both groups while applying strain bilaterally, showed a statistically significant difference in mean of micro strain between the Ball and the Magnetic attachment at the loaded side where the highest mean value of micro strain was found in the Ball while the least mean value of micro strain was found in Magnet attachment. According to Chao et al. and Mericske-Stern et al. ${ }^{(34,35)}$, the overdenture will tend to rotate anteriorly around a fulcrum line when posterior loads are applied. As a result of this rotation, the denture dis-engaged from the right side thus reduction in the micro-strain transmitted to the right implant and more microstrain induction in the left implant. Studies have shown less retentive forces in magnet attachments 
in comparison with other stud attachments ${ }^{(18,36)}$ hence explaining why less stresses were induced in the magnet attachment than the ball attachment ${ }^{(18-20)}$. There seems to be an association between the moment an attachment loses its retention and the amount of stresses conveyed to the bone/implant complex; the faster the attachment loses retention, the less the stress transmitted to the implant ${ }^{(36)}$.

\section{CONCLUSION}

Within the limitations of this study, it can be concluded that ball attachments induced higher micro-strain on the bone implant interface than the magnet attachment. The two main limitations of this study are: the physical properties of acrylic resin do not accurately simulate the complex nature of bone and osseointegration as well as the vertical load that was applied does not resemble the complex directions of forces that occur during mastication. As there is no one attachment that would fulfill the ideal requirements because each clinical situation is unique, careful selection of attachment is necessary to satisfy the patient's needs and expectations, as well as establishing a long term biologic and functional result.

\section{REFERENCES}

1. Misch, C.E, Maxillary Arch Implant Considerations: Fixed and Overdenture Prostheses, in Contemporary Implant Dentistry. 2008, St Louis: Elsevier Mosby. p. 367-388.

2. Fein, J.S. \& Carlsson, G.E. The McGill consensus statement on overdentures. In: Fein, J.S. \& Carlsson, G.E., eds. Implant Overdentures: The Standard of Care for Edentulous Patients, 2003; 155-157. Chicago: Quintessence Publishing Company.

3. Mumcu E, Bilhan H, Geckili O. The effect of attachment type and implant number on satisfaction and quality of life of mandibular implant-retained overdenture wearers. Gerodontology 2012; 29: 16-18.

4. Rismanchian M, Bajoghli F, Mostajeran Z, et al. Effect of implants on maximum bite force in edentulous patients. $\mathrm{J}$ Oral Implantol 2009; 35: 196-200.
5. Naert I, Alsaadi G, Quirynen M: Prosthetic aspects and patient satisfaction with two-implant-retained mandibular overdentures: a 10-year randomized clinical study. Int J Prosthodont 2004;17:401-410.

6. Ekelund J-A, Lindquist LW, Carlsson GE, et al. Implant Treatment in the Edentulous Mandible: A Prospective Study on Branemark System Implants over More than 20Years. Int J Prosthodont 2003; 16: 602-608.

7. Sadowsky, S.J. Treatment consideration for maxillary implant overdentures: a systemic review. Journal of Prosthetic Dentistry 2007; 97: 340-348.

8. Payne AG, Tawse-Smith A, Kumara R, Thomson WM, One-year prospective evaluation of the early loading of unsplinted conical Brånemark fixtures with mandibular overdentures immediately following surgery. Clin Implant Dent Relat Res. 2001;3(1):9-19.

9. Takahashi T, Gonda T, Tomita A, Maeda Y. Effect of Attachment Type on Implant Strain in Maxillary Implant Overdentures: Comparison of Ball, Locator, and Magnet Attachments. Part 2: Palateless Dentures. Int J Oral Maxillofac Implants. 2018;33 (2):357-364.

10. Fenlon MR, Palmer RM, Palmer P, et al: A prospective study of single stage surgery for implant supported overdentures. Clin Oral Implants Res 2002; 13:365-370.

11. Brosh T, Pilo R, Sudai D. The influence of abutment angulation on strains and stresses along the implant/ bone interface: comparison between two experimental techniques. J Prosthet Dent 1998;79:328-34.

12. Brunski, J. B. Avoid pitfalls of overloading and micromotion of intraosseous implants. Dent Implantol Update. 1993; 4(10): 77-81.

13. Miyata, T., Kobayashi Y., Araki H., et al. The influence of controlled occlusal overload on peri-implant tissue: a histologic study in monkeys. Int J Oral Maxillofac Implants. 1998; 13(5): 677-83.

14. Chung K-H, Whiting D, Kronstrom M, et al. Retentive characteristics of overdenture attachments during repeated dislodging and cyclic loading. Int J Prosthodont 2011; 24: 127-9.

15. Manju V, Sreelal T. Mandibular Implant-Supported Overdenture: An In Vitro Comparison of Ball, Bar, and Magnetic Attachments. J Oral Implantol 2013; 39:302-307.

16. Chu FCS, Deng FL, Siu ASC, et al. Implant-tissue supported, magnet-retained mandibular overdenture for an edentulous patient with Parkinson's disease: A clinical report. J Prosthet Dent 2004; 91: 219-222. 
17. Yang T, Maeda Y. Clinical performance and satisfaction of removable prostheses with self-adjusting magnetic attachments. J Prosthet Dent; 2014;111 (2): 131-135.

18. Tokuhisa M, Matsushita Y, Koyano K. In Vitro Study of a Mandibular Implant Overdenture Retained with Ball, Magnet, or Bar Attachments: Comparison of Load Transfer and Denture Stability. Int J Prosthodont 2003; 16: 128-134.

19. Takeshita S, Kanazawa M, Minakuchi S. Stress analysis of mandibular two-implant overdenture with different attachment systems. Dent Mater J 2011; 30: 928-934.

20. ELsyad MA, Errabti HM, Mustafa AZ, Mandibular Denture Base Deformation with Locator and Ball Attachments of Implant-Retained Overdentures. J Prosthodont. 2016 Dec;25 (8):656-664.

21. Takahashi T, Gonda T, Maeda Y. Effect of Attachment Type on Implant Strain in Maxillary Implant Overdentures: Comparison of Ball, Locator, and Magnet Attachments. Part 1. Overdenture with Palate. Int J Oral Maxillofac Implants. 2017;32 (6):1308-1314.

22. Anas El-Wegoud M, Fayyad A, Kaddah A, Nabhan A. Clin Implant Dent Relat Res. Bar versus ball attachments for implant-supported overdentures in complete edentulism: A systematic review. 2018 Apr; 20(2):243-250.

23. Karl M, Dickinson A, Holst S, Holst A. Biomechanical methods applied in dentistry: a comparative overview of photoelastic examinations, strain gauge measurements, finite element analysis and three-dimensional deformation analysis. Eur J Prosthodont Restor Dent 2009; 17:50-7.

24. Celland NL, Gilat A., McGumphy, EA, Brantley WA. A Photoelastic and strain gauge analysis of angled abutments for implant system. Int J Oral MaxilloFac Implants 1993, 8; 541-8.

25. Kim WD, Jacobson Z, Nathanson D. Invitro stress analysis of dental implants supporting screw retained and cement retained prostheses. Implant Dent 1999; 8 (2):141:51.

26. Stegaroiu, R., Khraisat, A., Nomura, S. and Miyakawa, O.: Influence of superstructure material on strain around an implant under two loading conditions: A technical investigation Int. J. Oral Maxillofac Implants. 2004: 19: 735.
27. Bidez MW, Misch CE: Force transfer in implant dentistry: basic concepts and principls. J Oral Implantol. 1992, 23:264-74.

28. Branemark PI,Zarb GA.,Alberktsson T. Tissue -integrated prostheses. Osseointegration in clinical Dentistry. Chicago: Quintessence, 1987.p129

29. Van Oosterwyck H, Duyck J, Vander Sloten J., Van der Perre G, De Cooman M., Lievens S. et al. The influence of bone mechanical properties and implant fixation upon bone loading around oral implants. Clin Oral Implants Res 1998;9:407-418.

30. Sheppard IM: Denture base dislodgment during mastication, J. Prosthet. Dent. 1963; 13:462-468.

31. Isidor F. Loss of osseointegration caused by occlusal load of oral implants. A clinical and radiographic study in monkeys. Clinical oral implants research 1996; 7:143-152.

32. Elsyad Ma, Elhddad Aa, Khirallah As. The effect of implant diameter on strain around implants retaining a mandibular overdenture with Locator attachments: An in vitro; study. Dent Mater J 2016; 35: 938-945.

33. Assuncao WG, Barao VA, Tabata LF, et al: Comparison between complete denture and implant-retained overdenture: effect of different mucosa thickness and resiliency on stress distribution. Gerodontology 2009; 26:273-281.

34. Chao, Y.L., Meijer, H.J., Van Oort, R.P., Versteegh, P.A. The incomprehensible success of the implant stabilised overden- ture in the edentulous mandible: a literature review on transfer of chewing forces to bone surrounding implants. Eur. J. Prosthodont. Restor. Dent.1995; 3 , 255-261.

35. Mericske-Stern, R., Piotti, M., Sirtes, G. 3-D in vivo force measurements on mandibular implants supporting overden- tures. A comparative study. Clin. Oral Implant. Res. 1996; 7, 387-396.

36. Petropoulos VC, Mante FK. Comparison of Retention and Strain Energies of Stud Attachments for Implant Overdentures. J Prosthodont 2011; 20: 286-293. 